\title{
Simultaneous temporal trends in dementia incidence and prevalence, 2005-2013: a population-based retrospective cohort study in Saskatchewan, Canada
}

\author{
Julie G. Kosteniuk, ${ }^{1}$ Debra G. Morgan, ${ }^{2}$ Megan E. O'Connell, ${ }^{3}$ Andrew Kirk, ${ }^{4}$ \\ Margaret Crossley, ${ }^{5}$ Gary F. Teare, ${ }^{6}$ Norma J. Stewart, ${ }^{7}$ Vanina Dal Bello-Haas, ${ }^{8}$ \\ Lesley McBain, ${ }^{9}$ Haizhen Mou, ${ }^{10}$ Dorothy A. Forbes, ${ }^{11}$ Anthea Innes ${ }^{12}$ \\ and Jacqueline M. Quail ${ }^{6}$ \\ ${ }^{1}$ Canadian Centre for Health and Safety in Agriculture, University of Saskatchewan, Saskatoon, Saskatchewan, Canada \\ ${ }^{2}$ Canadian Centre for Health and Safety in Agriculture, University of Saskatchewan, 103 Hospital Drive, Saskatoon, Saskatchewan, Canada \\ ${ }^{3}$ Department of Psychology, University of Saskatchewan, Saskatoon, Saskatchewan, Canada \\ ${ }^{4}$ Division of Neurology, College of Medicine, University of Saskatchewan, Saskatoon, Saskatchewan, Canada \\ ${ }_{5}^{5}$ Department of Psychology (Professor Emerita), University of Saskatchewan, Saskatoon, Saskatchewan, Canada \\ ${ }^{6}$ Saskatchewan Health Quality Council, Saskatoon, Saskatchewan, Canada \\ ${ }^{7}$ College of Nursing, University of Saskatchewan, Saskatoon, Saskatchewan, Canada \\ ${ }^{8}$ School of Rehabilitation Science, McMaster University, Hamilton, Ontario, Canada \\ ${ }^{9}$ Indigenous Studies, First Nations University, Prince Albert, Saskatchewan, Canada \\ ${ }^{10}$ Fohnson Shoyama Graduate School of Public Policy, University of Saskatchewan, Saskatoon, Saskatchewan, Canada \\ ${ }^{11}$ Faculty of Nursing, University of Alberta, Edmonton, Alberta, Canada \\ ${ }^{12}$ Faculty of Social Sciences, University of Stirling, Stirling, UK and Salford Institute for Dementia, University of Salford, Manchester, UK
}

Background: Original studies published over the last decade regarding time trends in dementia report mixed results. The aims of the present study were to use linked administrative health data for the province of Saskatchewan for the period 2005/2006 to 2012/2013 to: (1) examine simultaneous temporal trends in annual age- and sex-specific dementia incidence and prevalence among individuals aged 45 and older, and (2) stratify the changes in incidence over time by database of identification.

Methods: Using a population-based retrospective cohort study design, data were extracted from seven provincial administrative health databases linked by a unique anonymized identification number. Individuals 45 years and older at first identification of dementia between April 1, 2005 and March 31, 2013 were included, based on case definition criteria met within any one of four administrative health databases (hospital, physician, prescription drug, and long-term care).

Results: Between 2005/2006 and 2012/2013, the 12-month age-standardized incidence rate of dementia declined significantly by $11.07 \%$ and the 12 -month age-standardized prevalence increased significantly by $30.54 \%$. The number of incident cases decreased from 3,389 to 3,270 and the number of prevalent cases increased from 8,795 to 13,012 . Incidence rate reductions were observed in every database of identification.

Conclusions: We observed a simultaneous trend of decreasing incidence and increasing prevalence of dementia over a relatively short 8 -year time period from $2005 / 2006$ to $2012 / 2013$. These trends indicate that the average survival time of dementia is lengthening. Continued observation of these time trends is warranted given the short study period.

Key words: dementia, diagnosis, epidemiology, physician, hospital, long-term care, prescription drug, administrative data

Correspondence should be addressed to: Julie G. Kosteniuk, Canadian Centre for Health and Safety in Agriculture, University of Saskatchewan, Saskatoon, Saskatchewan, Canada. Phone: 306-966-8773; Fax: 306-966-8774. Email: julie.kosteniuk@usask.ca. Received 5 Aug 2015; revision requested 8 Oct 2015; revised version received 16 Mar 2016; accepted 26 Apr 2016. First published online 29 June 2016.

\section{Introduction}

Dementia refers to a "clinical syndrome of cognitive decline" that interferes with daily functioning and generally occurs alongside behavior and personality changes; the decline must not be the result of delirium or another condition (i.e. 
medical, neurological, or psychiatric) (Chertkow et al., 2013). The most common causes of dementia are Alzheimer's disease (50-75\%), vascular dementia (20-30\%), frontotemporal dementia (5-10\%), and dementia with Lewy bodies $(<5 \%)$ [Alzheimer's Disease International (ADI), 2014]).

The estimated global number of incident and prevalent cases of dementia in 2015 was 9.9 million and 46.8 million respectively (ADI, 2015). Worldwide, the age- and gender-standardized incidence of dementia among adults aged 6064 was an estimated 3.9 per 1,000 person years, doubling with every 6.3 years of age to 104.8 per 1,000 person years among adults aged 90 and older (ADI, 2015). High income countries generally exhibited higher incidence than low and middle income countries, particularly across older age groups. Furthermore, the estimated agestandardized prevalence of dementia ranged from $1.3 \%$ among those aged $60-64$ to $27.1 \%$ in those aged 90 and older in Central Europe $(4.7 \%$ aged 60 and older), and from $2.2 \%$ among those aged 60 64 to $29.4 \%$ in those aged 85 and older in North Africa/Middle East (8.7\% aged 60 and older) (ADI, 2015).

Original studies published over the last decade regarding time trends in dementia have reported mixed results in several different regions of the world. Key studies provide evidence of declining incidence in Rochester, United States (US) (Rocca et al., 2011) and Rotterdam, the Netherlands (Schrijvers et al., 2012). Further studies indicate stable (Hall et al., 2009) or declining dementia prevalence in a national US sample (Langa et al., 2008), stable prevalence in a German sample (Doblhammer et al., 2015), and declining prevalence in Zaragoza, Spain (Lobo et al., 2007) and regions of England and Wales (Matthews et al., 2013). In contrast, other research reveals increasing dementia prevalence in northern Sweden (Mathillas et al., 2011), a national sample of France (Bertrand et al., 2013), Hisayama, Japan (Sekita et al., 2010), and the province of Alberta, Canada (Jacklin et al., 2013). Notably, the number of prevalent dementia cases is forecast to increase to a greater extent in low and middle (227-264\%) versus high income countries $(116 \%)$ by 2050 (ADI, 2015).

To the best of our knowledge, two other original studies that examined simultaneous trends in dementia incidence and prevalence have been published within the last 10 years (Qiu et al., 2013; $\mathrm{Ng}$ et al., 2015). In the first, a prospective cohort study of two 6-year cohorts aged 75 and older from 1987-1989 and 2001-2004 in central Stockholm, Sweden, Qiu et al. (2013) found that age-standardized dementia prevalence remained stable. Dementia incidence was not assessed directly; however, survival time based on 6-year follow-up was significantly longer for the later than earlier cohort, leading Qiu and colleagues to suggest that incidence decreased over the study period. In the second, a report based on a retrospective administrative health data study of the population aged 40 and older in Ontario, Canada, Ng et al. (2015) concluded that age-and sex-adjusted dementia prevalence increased over a 7 -year period between 2004/2005 and 2010/2011, from 16.3 to 19.7 per 1,000 persons, and age- and sex-adjusted incidence decreased from 5.1 to 5.0 per 1,000 persons.

The value of using administrative health data to examine temporal trends in dementia incidence and prevalence can be illustrated in three key ways. The first of these is the investigation of possible impacts of population-level trends in modifiable risk factors throughout the lifecourse (early, midlife, and late life), on the incidence and prevalence of dementia (ADI, 2014). Currently, moderate to robust evidence exists for four domains of modifiable dementia risk factors: developmental (e.g. occupational status, education), psychological (e.g. depression, anxiety, sleep disorders), lifestyle or behavior (e.g. cigarette use), and cardiovascular (e.g. obesity, cholesterol, hypertension, diabetes) (ADI, 2014). Downward trends in dementia incidence over time in populations with documented improvements in these risk factors (e.g. improved education levels and reduced hypertension) would provide further evidence of the association between dementia and these risk factors. The second use of administrative health data in secular trend studies is to provide evidence for the association between trends in dementia and other population-level trends and interventions, including demographics (e.g. aging; Langa et al., 2008; Sekita et al., 2010); life expectancy (Schrijvers et al., 2012; Qiu et al., 2013); treatment of chronic diseases (e.g. use of statins; Langa et al., 2008; Hall et al., 2009; and hypertensive medications; Langa et al., 2008); treatment of cardiovascular diseases (Mathillas et al., 2011; Schrijvers et al., 2012); health and social care for individuals with dementia (Sekita et al., 2010; Mathillas et al., 2011); and standard of living (Langa et al., 2008). Third, current dementia projection methods are typically based on the assumption that certain factors will remain stable over time, such as age-specific dementia prevalence (ADI, 2015), mortality, and dementia risk factors (except demographics) (Rocca et al., 2011). Such projections do not adequately account for "changing patterns in risk factors" (Norton et al., 2013), i.e. trends in population-level factors, 
that can be accounted for in studies based on administrative health data.

There have been several recent original Canadian studies concerning dementia prevalence, at the provincial level (Fransoo et al., 2009; Martens et al., 2010; Gill et al., 2011; Chartier et al., 2012; Jacklin et al., 2013). However, there have been few Canadian studies of trends in dementia prevalence (Jacklin et al., 2013; Ng et al., 2015) and incidence (CSHA 2000; Tyas et al., 2006; Ng et al., 2015). Using linked administrative health data for the province of Saskatchewan for the time period between 2005/2006 and 2012/2013, the purposes of this study were to: (1) examine simultaneous age- and sex-specific temporal trends in dementia incidence and prevalence among individuals aged 45 and older, and (2) stratify any changes in incidence over time by database of identification.

\section{Methods}

\section{Setting}

The province of Saskatchewan is the middle of three Canadian prairie provinces and covers $651,000 \mathrm{~km}^{2}$ (Saskatchewan Bureau of Statistics, 2015). Between 2006 and 2013, the province's population grew 116,021 (11.7\%) from 992,302 to $1,108,303$ (Statistics Canada, 2014a). The proportion of the population aged 45-64 grew from $25.1 \%$ to $26.1 \%$ while the proportion aged 65 and older declined from $15 \%$ to $14.4 \%$. The province's population growth of 74,047 between 2006 and 2011 (Saskatchewan Bureau of Statistics, 2014) was largely attributable to interprovincial migration $(12,000 ; 16.2 \%)$ and immigration $(28,000 ; 37.8 \%)$, with three times more immigrants during this period compared to 2001-2006 $(9,800)$ (Statistics Canada, 2012). Among the 13 provinces and territories, Saskatchewan's growth during 2006-2011 was third largest at $6.7 \%$, and larger than the national average at $5.9 \%$ (Statistics Canada, 2012).

Nearly all (99\%) Saskatchewan residents receive provincial healthcare coverage (Downey et al., 2005) and constitute the "covered population" for the present study. Federally insured residents (federal prison inmates, members of the Canadian Forces, and Royal Canadian Mounted Police) are not included in the covered population (Saskatchewan Ministry of Health, 2012); however, their information is captured in hospital data. The Registered Indian population is not covered by the province's Prescription Drug Plan (Saskatchewan Ministry of Health, 2010) and therefore are not included in the Prescription Drug Database employed in the current study. Approximately 13\% of the Saskatchewan population in 2012 were classified as Registered Indians (Aboriginal Affairs and Northern Development Canada, 2013).

\section{Data sources}

Data were extracted from seven provincial administrative health databases linked by a unique anonymized personal health services number (Saskatchewan Ministry of Health, 2010). Databases describing the demographic characteristics and insurance coverage for the population of Saskatchewan included the Person Health Registration System, Saskatchewan Resident Geography Database, and the Vital Statistics database. The databases from which the cohort were identified were the Hospital Discharge Abstract Database, Physician Services Claims Database, Prescription Drug Database, and the Resident Assessment Instrument Minimum Data Set (RAI-MDS), i.e. Long-term Care Database.

From 2002 onwards, the Hospital Discharge Abstract Database includes 5-digit ICD-10-CA codes to record up to 25 diagnoses per record. The Physician Services Claims Database includes information used by physicians to claim payment from the provincial government for services provided to patients and a 3-digit ICD9 diagnosis code associated with the service (maximum of one diagnosis code per service claim) (Saskatchewan Ministry of Health, 2010). The Prescription Drug Database includes information about drugs dispensed such as classification of the drug and drug identification number (DIN), with only Saskatchewan Formulary drugs eligible for coverage. The Long-term Care Database contains assessment information collected at admission to a residential care facility, at regular threemonth intervals, and upon significant changes in clinical status (Morris et al., 2010). Admission and quarterly assessment data were included in the present study.

\section{Cohort}

The case definition algorithm in the present study was developed over a three-stage process. Further details regarding the algorithm used in the current study are available elsewhere (Kosteniuk et al., 2015).

Individuals aged 45 years or older at their firstever recorded identification of dementia between April 1, 2005 and March 31, 2013 constituted the cohort. "Young onset dementia" (i.e. before age of 65 ) is estimated to affect approximately $6-9 \%$ of all prevalent cases (WHO, 2012) yet the true prevalence is unknown because epidemiological studies of dementia generally exclude those younger 
than 65 years (Lambert et al., 2014). Given the distinct needs and experiences of individuals with young onset dementia and their families and the deficiency of research in this area (Ducharme et al., 2014), as well as the need for a complete epidemiological picture, we chose to employ an age cut-off of 45 in the present study.

A "washout" period of 5 years prior to the first identification of dementia was used to ensure that we correctly identified incident dementia. Individuals entered the cohort either on their index date or April 1, 2005, whichever was later. They remained in the cohort until the earliest occurrence of any of the following: death, loss of their insurance (i.e. gap in insurance coverage of more than 3 days), or March 31, 2013. Individuals with a gap in their insurance of more than 3 days were not re-entered into the cohort.

Individuals were identified as a dementia case if they met at least one of the following criteria: $\geq 1$ physician visit (ICD-9 codes 290, 294, 331, 797 ); $\geq 1$ hospitalization (ICD-10-CA codes F00, F01, F02, F03, F04, F05.1, F06.8, F06.9, F09, F10.6, F10.7, F18.6, F18.7, F19.6, F19.7, G30, G31.0, G31.1, G91, R54); $\geq 1$ prescription for a cholinesterase inhibitor (Aricept DINs 02232043, 02232044; Exelon DINs: 02242115-02242118, 02245240; Reminyl DINs: 02244298-02244300, 02266717, 02266725, 02266733); or - in the Longterm Care Database - a Cognitive Performance Scale (CPS) score of 2 or over and/or a disease category of Alzheimer's disease or dementia other than Alzheimer's disease.

Physician and hospital data are commonly used in administrative health data studies of dementia epidemiology, requiring at minimum one physician visit or hospitalization to identify a dementia case (Fransoo et al., 2009; Martens et al., 2010; Gill et al., 2011; Chartier et al., 2012; Manitoba Centre for Health Policy, 2012; Jacklin et al., 2013). Alzheimer's disease does not have a diagnostic test for confirmation purposes (St Germaine-Smith et al., 2012) and underdiagnosis of dementia is a significant problem (Boustani et al., 2003; ADI, 2011; Connolly et al., 2011). Therefore, the case definition for the present study prioritized sensitivity over specificity by including prescription drug and long-term care data to account for dementia cases that may not have been identified in physician or hospital data. Other medications may be used to treat Alzheimer's disease (e.g. memantine); however, the three medications included in the present study (Aricept, Exelon, and Reminyl) are the only cholinesterase inhibitors prescribed in Canada (Lee et al., 2011) and are the most commonly used treatment of Alzheimer's disease in the country (Hogan, 2014).
Moreover, cholinesterase inhibitors are typically not used for the treatment of other conditions and have been shown to have limited value in the treatment of attention-deficit hyperactivity disorder in a recent review (Bidwell et al., 2011).

In the Long-term Care Database, the CPS consists of five measures in total: one of comatose status, two cognition (short term memory and cognitive skills for daily decision making), one communication, and one measure of activities of daily living (Morris et al., 1994). The CPS categorizes individuals into one of seven levels of cognitive performance based on a score of 0 to 6 (Intact $=0 ; 1=$ Borderline intact; $2=$ Mild impairment; $3=$ Moderate impairment; $4=$ Moderate severe impairment; $5=$ Severe impairment; $6=$ Very severe impairment). A CPS score of 2 or higher is equivalent to an average Mini-Mental State Examination score of 19 or lower (Bartfay et al., 2013). This cutoff indicates dementia at the moderate to severe stage (Perneczky et al., 2006) and possible mild to very severe impairment (Morris et al., 1994). A CPS score of 2 or higher has been validated against physician diagnosis and found to be $68 \%$ sensitive and $92 \%$ specific in detecting dementia (Travers et al., 2013), and against the Cambridge Examination for Mental Disorders of the ElderlyRevised (CAMDEX-R) and found to be $81 \%$ sensitive and $80 \%$ specific in detecting cognitive impairment (Paquay et al., 2007).

\section{Independent variables}

Age, sex, and administrative health database of first identification were the three independent variables included in the analysis. Age was represented by the categories of 45-54, 55-64, 65-74, 75-84, and 85 years and older. The four administrative health datasets included hospital, physician, prescription drug, and long-term care.

\section{Statistical analysis}

The age structure of the total cohort was used to adjust the sex-specific incidence rates and prevalence for age, and 95\% confidence intervals (CI) were calculated for all crude and agestandardized rates.

Incident cases were identified for each 12-month period between April 1, 2005 and March 31, 2013. Incident cases met the case definition criteria and had not been previously identified during the washout period between April 1, 2000 and March 31, 2005. The numerator for each 12month incidence rate was the number of people alive on April 1 of each year, who also met the case definition of dementia between April 1 of 


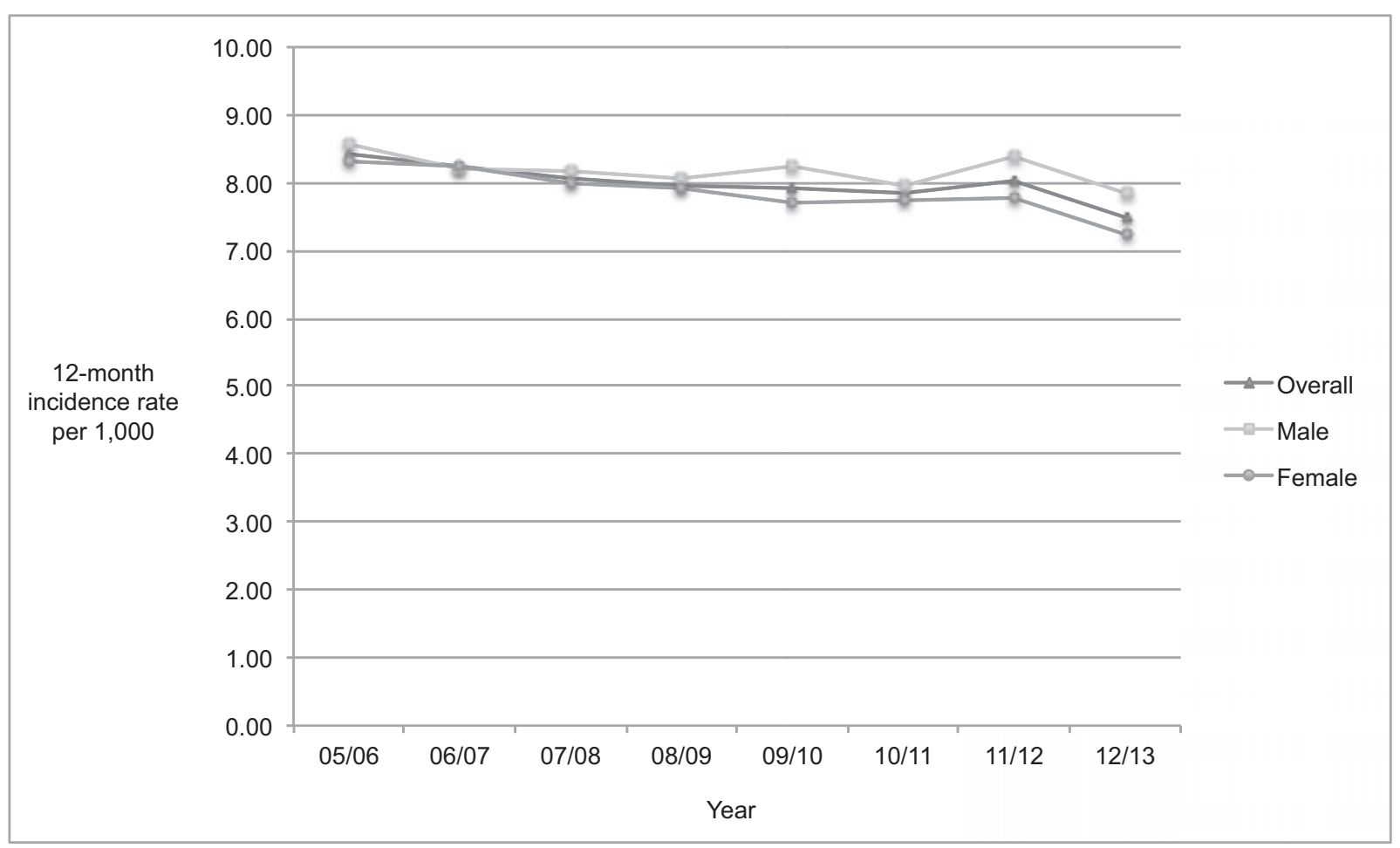

Figure 1. Age-standardized 12-month incidence rate of dementia among adults 45 years of age and older, Saskatchewan, from $2005 / 2006$ to $2012 / 2013$.

that year and March 31 of the following year. The denominator was the population at risk of developing incident dementia (i.e. after removing individuals with prevalent dementia for the same period, the remaining were aged 45 years or older on April 1 of each year with at least one day of health insurance coverage for the 12-month period).

Prevalent cases met the case definition criteria for each 12-month period from April 1 to March 31 for the years 2005 to 2013. The numerator for each 12-month prevalence was the number of people alive on April 1 of each year who met the case definition criteria at any time prior to April 1 of that year. Those individuals at risk for prevalent dementia (i.e. all individuals in the covered population aged 45 years or older on April 1 of each year with at least one day of health insurance coverage for the 12 -month period) constituted the denominator.

For incidence and prevalence, we calculated the percentage changes between 2005/2006 and $2012 / 2013$ in absolute number $(n)$, percentage, population, and age-standardized rate per 1,000, by dividing the difference between the two figures by the earlier figure and multiplying by 100 . Percentage changes in age-standardized incidence rates and prevalence per 1,000 were compared for significant differences $(p<0.05)$ using the $\chi^{2}$ test, and $95 \%$ CI were calculated for all crude and age-standardized rates. All analyses were completed with SAS 9.3 (SAS Institute Inc, Cary NC).

\section{Ethical considerations}

The University of Saskatchewan Biomedical Research Ethics Board granted ethics approval for this study (Bio-REB \#12-339).

\section{Results}

\section{Incidence}

As shown in Figure 1, the overall age-standardized incidence rate of dementia among individuals 45 years and older declined gradually and steadily from $2005 / 2006$ until 2010/2011, rising slightly in $2011 / 2012$ before dropping again in 2012/2013. Table 1 indicates that the annual population rose steadily each year between 2005/2006 to $2012 / 2013$. As shown in Table 2 , the population increased by $11.38 \%$ from 403,123 to 449,012 while the absolute number of overall incident cases dropped by $3.51 \%$ from 3,389 to 3,270 between $2005 / 2006$ and 2012/2013. The overall agestandardized incidence rate declined significantly by $11.07 \%(p<0.0001)$ from 8.41 to 7.48 per 1,000 over the 8-year period.

Table 2 shows that although the female and male populations increased between 2005/2006 
Table 1. Twelve-month incidence and prevalence of dementia among adults 45 years of age and older, Saskatchewan, from 2005/2006 to $2012 / 2013$

\begin{tabular}{|c|c|c|c|c|c|c|c|c|}
\hline & $2005 / 2006$ & $2006 / 2007$ & $2007 / 2008$ & 2008/2009 & $2009 / 2010$ & $2010 / 2011$ & $2011 / 2012$ & $2012 / 2013$ \\
\hline \multicolumn{9}{|l|}{ Incidence } \\
\hline Total population at risk & 403,123 & 407,409 & 417,605 & 426,839 & 431,628 & 438,941 & 445,187 & 449,012 \\
\hline Incident cases & 3,389 & 3,338 & 3,314 & 3,312 & 3,320 & 3,346 & 3,475 & 3,270 \\
\hline \multicolumn{9}{|l|}{ Crude incidence } \\
\hline Female & $9.77(9.35-10.20)$ & $9.66(9.24-10.08)$ & $9.25(8.85-9.67)$ & $9.05(8.66-9.46)$ & $8.80(8.41-9.20)$ & $8.88(8.49-9.27)$ & $8.89(8.51-9.28)$ & $8.25(7.88-8.63)$ \\
\hline Male & $6.96(6.59-7.34)$ & $6.64(6.28-7.00)$ & $6.54(6.19-6.90)$ & $6.40(6.06-6.75)$ & $6.53(6.19-6.88)$ & $6.31(5.98-6.65)$ & $6.68(6.34-7.03)$ & $6.28(5.95-6.62)$ \\
\hline Overall & $8.41(8.13-8.69)$ & $8.19(7.92-8.47)$ & $7.94(7.67-8.21)$ & $7.76(7.50-8.03)$ & $7.69(7.43-7.96)$ & $7.62(7.37-7.88)$ & $7.81(7.55-8.07)$ & $7.04(7.04-7.54)$ \\
\hline \multicolumn{9}{|c|}{ Age-standardized incidence rate (to $2005 / 2006$ total Sask. population) } \\
\hline Female & $8.31(7.95-8.68)$ & $8.26(7.91-8.63)$ & $8.00(7.65-8.36)$ & $7.90(7.56-8.26)$ & $7.72(7.38-8.07)$ & $7.75(7.42-8.10)$ & $7.79(7.46-8.14)$ & $7.23(6.91-7.56)$ \\
\hline Male & $8.56(8.11-9.02)$ & $8.20(7.76-8.66)$ & $8.19(7.75-8.64)$ & $8.05(7.63-8.50)$ & $8.23(7.80-8.67)$ & $7.95(7.53-8.39)$ & $8.38(7.96-8.82)$ & $7.84(7.43-8.26)$ \\
\hline Overall & $8.41(8.13-8.69)$ & $8.24(7.96-8.52)$ & $8.07(7.80-8.35)$ & $7.96(7.69-8.24)$ & $7.92(7.65-8.19)$ & $7.83(7.57-8.10)$ & $8.03(7.76-8.30)$ & $7.48(7.22-7.74)$ \\
\hline \multicolumn{9}{|l|}{ Prevalence } \\
\hline Total population at risk & 411,918 & 417,297 & 428,269 & 438,069 & 443,466 & 451,222 & 457,822 & 462,024 \\
\hline Prevalent cases & 8,795 & 9,888 & 10,664 & 11,230 & 11,838 & 12,281 & 12,635 & 13,012 \\
\hline \multicolumn{9}{|l|}{ Crude prevalence } \\
\hline Female & $26.00(25.33-26.68)$ & $28.84(28.14-29.55)$ & $30.47(29.76-31.19)$ & $31.46(30.74-32.19)$ & $32.87(32.14-33.61)$ & $33.32(32.60-34.06)$ & $33.79(33.06-34.53)$ & $34.19(33.46-34.93)$ \\
\hline Male & $16.36(15.81-16.93)$ & $18.16(17.58-18.76)$ & $18.94(18.36-19.54)$ & $19.42(18.84-20.02)$ & $20.12(19.53-20.72)$ & $20.74(20.15-21.35)$ & $21.06(20.47-21.67)$ & $21.82(21.22-22.43)$ \\
\hline Overall & $21.35(20.91-21.80)$ & $23.70(23.24-24.16)$ & $24.90(24.44-25.37)$ & $25.64(25.17-26.11)$ & $26.69(26.22-27.17)$ & $27.22(26.74-27.70)$ & $27.60(27.13-28.08)$ & $28.16(27.69-28.64)$ \\
\hline \multicolumn{9}{|c|}{ Age-standardized prevalence (to $2005 / 2006$ total Sask. population) } \\
\hline Female & $21.88(21.31-22.45)$ & $24.04(23.45-24.63)$ & $25.04(24.85-26.05)$ & $26.35(25.75-26.96)$ & $27.37(26.77-27.99)$ & $27.59(26.99-28.20)$ & $28.04(27.44-28.65)$ & $28.33(27.73-28.94)$ \\
\hline Male & $20.51(19.81-21.22)$ & $22.65(21.92-23.39)$ & $23.81(23.07-24.86)$ & $24.53(23.80-25.29)$ & $25.35(24.60-26.10)$ & $26.06(25.31-26.82)$ & $26.31(25.57-27.07)$ & $27.15(26.40-27.91)$ \\
\hline Overall & $21.35(20.91-21.80)$ & $23.50(23.05-23.97)$ & $24.82(24.35-25.29)$ & $25.65(25.19-26.13)$ & $26.60(26.13-27.07)$ & $27.00(26.53-27.48)$ & $27.37(26.90-27.85)$ & $27.87(27.40-28.35)$ \\
\hline
\end{tabular}


Table 2. Change in 12-month incidence of dementia among adults 45 years of age and older, Saskatchewan, 2005/2006 to 2012/2013

\begin{tabular}{|c|c|c|c|c|c|c|c|c|c|c|c|c|c|c|c|}
\hline & \multicolumn{5}{|c|}{$2005 / 2006 N=3,389$} & \multicolumn{5}{|c|}{$2012 / 2013 N=3,270$} & \multicolumn{5}{|c|}{ CHANGE FROM 2005/2006 TO $2012 / 2013$ (\%) } \\
\hline & \multirow[b]{2}{*}{$n$} & \multirow[b]{2}{*}{$\%$} & \multirow[b]{2}{*}{ POPULATION } & \multirow[b]{2}{*}{ CRUDE RATE PER 1,000} & AGE-STANDARDIZED & \multirow[b]{2}{*}{$n$} & \multirow[b]{2}{*}{$\%$} & \multirow[b]{2}{*}{ POPULATION } & \multirow[b]{2}{*}{ CRUDE RATE PER 1,000} & \multirow{2}{*}{$\begin{array}{l}\text { AGE-STANDARDIZED } \\
\text { RATE PER } 1,000\end{array}$} & \multirow[b]{2}{*}{$n$} & \multirow[b]{2}{*}{$\%$} & \multirow[b]{2}{*}{ POPULATION } & \multirow{2}{*}{$\begin{array}{l}\text { AGE-STAND. } \\
\text { RATE PER } \\
1,000\end{array}$} & \multirow[b]{2}{*}{$p$ VALUE ${ }^{a}$} \\
\hline & & & & & RATE PER 1,000 & & & & & & & & & & \\
\hline Female & 2,030 & 59.89 & 207,766 & $9.77(9.35-10.20)$ & $8.31(7.95-8.68)$ & 1,887 & 57.71 & 228,782 & $8.25(7.88-8.63)$ & $7.23(6.91-7.56)$ & -7.04 & -3.64 & 10.12 & -12.97 & $<0.0001$ \\
\hline Male & 1,359 & 40.10 & 195,357 & $6.96(6.59-7.34)$ & $8.56(8.11-9.02)$ & 1,383 & 42.29 & 220,230 & $6.28(5.95-6.62)$ & $7.84(7.43-8.26)$ & 1.77 & 5.46 & 12.73 & -8.39 & 0.0072 \\
\hline \multicolumn{16}{|l|}{ Database } \\
\hline Physician & 1,023 & 30.19 & 403,123 & 2.54 & $\mathrm{n} / \mathrm{a}$ & 979 & 29.94 & 449,012 & 2.18 & $\mathrm{n} / \mathrm{a}$ & -4.30 & -0.83 & 11.38 & $-14.17^{\mathrm{b}}$ & 0.0007 \\
\hline Hospital & 964 & 28.44 & 403,123 & 2.39 & $\mathrm{n} / \mathrm{a}$ & 933 & 28.53 & 449,012 & 2.08 & $\mathrm{n} / \mathrm{a}$ & -3.22 & 0.32 & 11.38 & $-12.97^{\mathrm{b}}$ & 0.0022 \\
\hline Prescription Drug & 204 & 6.02 & 403,123 & 0.51 & $\mathrm{n} / \mathrm{a}$ & 214 & 6.54 & 449,012 & 0.48 & $\mathrm{n} / \mathrm{a}$ & 4.90 & 8.64 & 11.38 & $-5.88^{\mathrm{b}}$ & 0.5376 \\
\hline LTC & 1,198 & 35.35 & 403,123 & 2.97 & $\mathrm{n} / \mathrm{a}$ & 1,144 & 34.98 & 449,012 & 2.55 & $\mathrm{n} / \mathrm{a}$ & -4.51 & -1.05 & 11.38 & $-14.14^{\mathrm{b}}$ & 0.0002 \\
\hline \multicolumn{16}{|l|}{ Female } \\
\hline $45-54$ & 35 & 1.72 & 75,340 & $0.46(0.32-0.65)$ & $0.47(0.32-0.65)$ & 37 & 1.96 & 75,597 & $0.49(0.34-0.67)$ & $0.46(0.32-0.63)$ & 5.71 & 13.95 & 0.34 & -1.46 & 0.8249 \\
\hline $55-64$ & 60 & 2.96 & 51,927 & $1.16(0.88-1.49)$ & $1.15(0.88-1.48)$ & 85 & 4.50 & 67,958 & $1.25(1.00-1.55)$ & $1.23(0.99-1.53)$ & 41.67 & 52.03 & 30.87 & 7.16 & 0.6390 \\
\hline $65-74$ & 178 & 8.77 & 36,476 & $4.88(4.19-5.65)$ & $4.85(4.17-5.62)$ & 165 & 8.74 & 42,193 & $3.91(3.34-4.55)$ & $4.10(3.50-4.78)$ & -7.30 & -0.34 & 15.67 & -15.40 & 0.0396 \\
\hline $75-84$ & 656 & 32.32 & 29,487 & $22.25(20.59-24.00)$ & $21.91(20.28-23.63)$ & 539 & 28.56 & 27,767 & $19.41(17.82-21.10)$ & $19.03(17.47-20.69)$ & -17.84 & -11.63 & -5.83 & -13.15 & 0.0177 \\
\hline $85+$ & 1,101 & 54.24 & 14,536 & $75.74(71.49-80.16)$ & $74.53(70.35-78.88)$ & 1,061 & 56.22 & 15,267 & $69.50(65.51-73.65)$ & $65.61(61.85-69.53)$ & -3.63 & 3.65 & 5.03 & -11.97 & 0.0377 \\
\hline All ages & 2,030 & 100.00 & 207,766 & $9.77(9.35-10.20)$ & $8.31(7.95-8.68)$ & 1,887 & 100.00 & 228,782 & $8.25(7.88-8.63)$ & $7.23(6.91-7.56)$ & -7.04 & 0 & 10.12 & -12.97 & $<0.0001$ \\
\hline \multicolumn{16}{|l|}{ Male } \\
\hline $45-54$ & 42 & 3.09 & 77,416 & $0.54(0.39-0.73)$ & $0.54(0.39-0.73)$ & 33 & 2.39 & 77,592 & $0.43(0.29-0.60)$ & $0.40(0.27-0.56)$ & -21.43 & -22.65 & 0.23 & -26.24 & 0.294 \\
\hline $55-64$ & 74 & 5.45 & 52,879 & $1.40(1.10-1.76)$ & $1.40(1.10-1.76)$ & 92 & 6.65 & 69,958 & $1.32(1.06-1.61)$ & $1.30(1.59-1.05)$ & 24.32 & 22.02 & 32.30 & -7.51 & 0.6903 \\
\hline $65-74$ & 178 & 13.10 & 34,121 & $5.22(4.48-6.04)$ & $5.25(4.51-6.08)$ & 164 & 11.86 & 41,005 & $4.00(3.41-4.66)$ & $4.25(3.63-4.96)$ & -7.87 & -9.47 & 20.18 & -18.97 & 0.0136 \\
\hline $75-84$ & 499 & 36.72 & 23,228 & $21.48(19.66-23.43)$ & $21.91(20.05-23.89)$ & 475 & 34.35 & 22,849 & $20.79(18.98-22.72)$ & $20.86(1905-22.80)$ & -4.81 & -6.45 & -1.63 & -4.77 & 0.6046 \\
\hline $85+$ & 566 & 41.65 & 7,713 & $73.38(67.66-79.43)$ & $75.70(69.79-81.93)$ & 619 & 44.76 & 8,826 & $70.13(64.89-75.66)$ & $71.46(66.12-77.09)$ & 9.36 & 7.47 & 14.43 & -5.60 & 0.4201 \\
\hline All ages & 1,359 & 100 & 195,357 & $6.96(6.59-7.34)$ & $8.56(8.11-9.02)$ & 1,383 & 100.00 & 220,230 & $6.28(5.95-6.62)$ & $7.84(7.43-8.26)$ & 1.77 & 0 & 12.73 & -8.39 & 0.0072 \\
\hline \multicolumn{16}{|l|}{ Overall } \\
\hline $45-54$ & 77 & 2.27 & 152,756 & $0.50(0.40-0.63)$ & $0.50(0.40-0.63)$ & 70 & 2.14 & 153,189 & $0.46(0.36-0.58)$ & $0.43(0.33-0.54)$ & -9.09 & -5.73 & 0.28 & -14.96 & 0.5521 \\
\hline $55-64$ & 134 & 3.95 & 104,806 & $1.28(1.07-1.51)$ & $1.28(1.07-1.51)$ & 177 & 5.41 & 137,916 & $1.28(1.10-1.49)$ & $1.27(1.09-1.47)$ & 32.09 & 36.96 & 31.59 & -0.91 & 0.9737 \\
\hline $65-74$ & 356 & 10.50 & 70,597 & $5.04(4.53-5.59)$ & $5.04(4.53-5.59)$ & 329 & 10.06 & 83,198 & $3.95(3.54-4.40)$ & $4.18(3.74-4.65)$ & -7.58 & -4.19 & 17.85 & -17.16 & 0.0014 \\
\hline $75-84$ & 1,155 & 34.08 & 52,715 & $21.91(20.68-23.20)$ & $21.91(20.68-23.20)$ & 1,014 & 31.01 & 50,616 & $20.03(18.83-21.29)$ & $19.85(18.66-21.09)$ & -12.21 & -9.01 & -3.98 & -9.42 & 0.0354 \\
\hline $85+$ & 1,667 & 49.19 & 22,249 & $74.92(71.50-78.46)$ & $74.92(71.50-78.46)$ & 1,680 & 51.38 & 24,093 & $69.73(66.55-73.02)$ & $67.65(64.56-70.84)$ & 0.78 & 4.45 & 8.29 & -9.70 & 0.0309 \\
\hline All ages & 3,389 & 100 & 403,123 & $8.41(8.13-8.69)$ & $8.41(8.13-8.69)$ & 3,270 & 100 & 449,012 & $7.28(7.04-7.54)$ & $7.48(7.22-7.74)$ & -3.51 & 0 & 11.38 & -11.07 & $<0.0001$ \\
\hline
\end{tabular}

${ }^{a}$ Test of difference between age-standardized dementia incidence rate in 2005/2006 versus 2012/2013.

${ }^{b}$ Change in crude rate per 1,000 . 


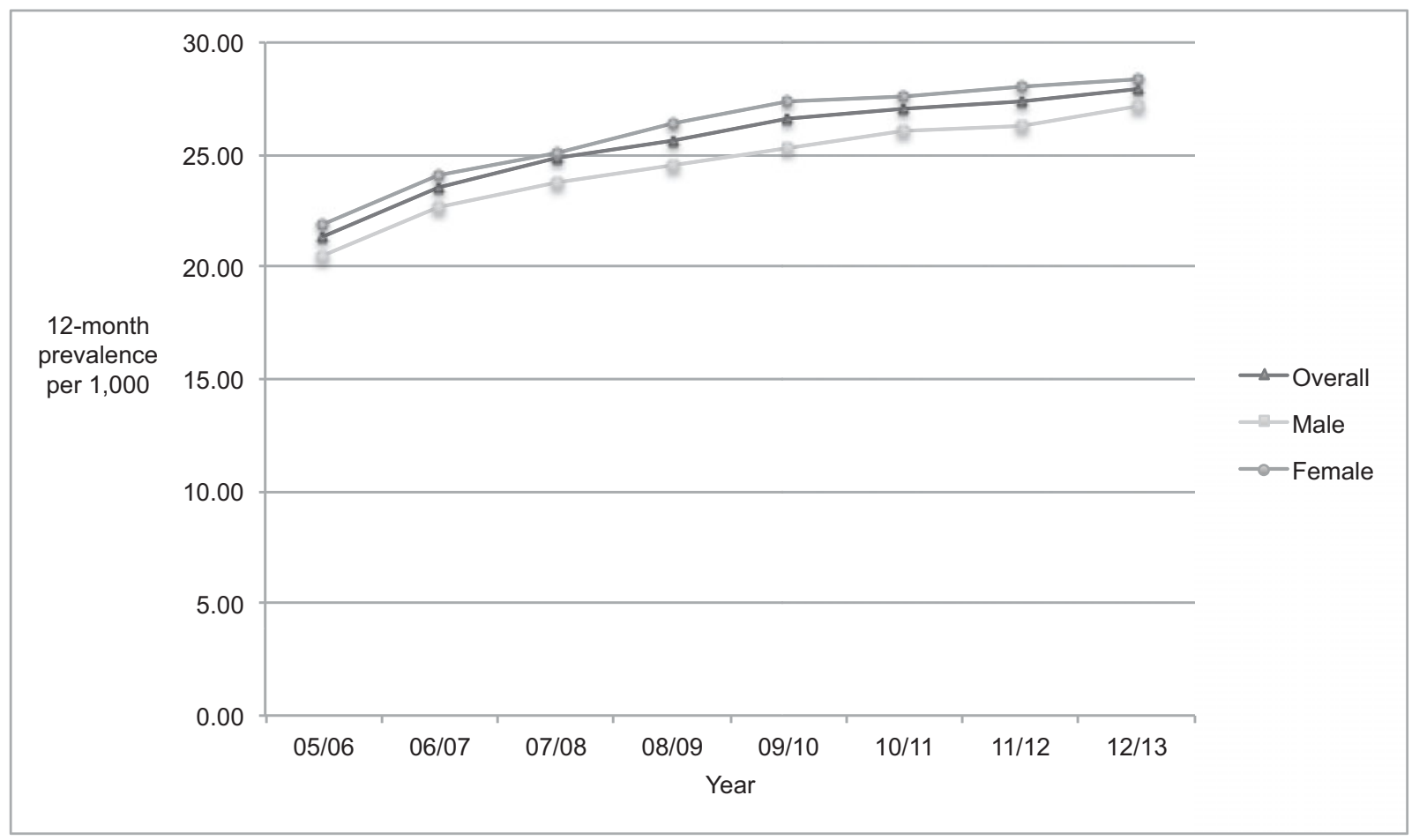

Figure 2. Age-standardized 12-month prevalence of dementia among adults 45 years of age and older, Saskatchewan, from $2005 / 2006$ to $2012 / 2013$.

and $2012 / 2013$ (10.12\% and $12.73 \%$ respectively), the absolute number of incident cases among females dropped while the absolute number of incident cases among males rose. Consequently, the age-standardized incidence rate decreased more markedly among females than males, dropping significantly by $12.97 \%(p<0.0001)$ among females (from 8.31 to 7.23 per 1,000) compared to $8.39 \%(p=0.0072)$ among males (from 8.56 to 7.84 per 1,000$)$. The proportion of incident cases attributed to females versus males dropped as well, by $3.66 \%$ from $59.89 \%$ to $57.71 \%$. The age-standardized incidence rate was slightly higher among males than females in 2005/2006 (8.56 vs. 8.31 per 1,000 ) and remained so in $2012 / 2013$ (7.84 vs. 7.23 per 1,000$)$.

Overall mean age at identification in 2005/2006 $(81.67+9.98$ years $)$ did not change significantly $(p=0 . \overline{24})$ in $2012 / 2013(81.97+10.70$ years $)$. As shown in Table 2, the population changed most substantially in the 55-64 and 65-74 age groups, increasing $16-31 \%$ among females and $20-32 \%$ among males. Despite this, the age-standardized incidence rate in the 55-64 age group did not change significantly over time for either sex. Among females, significant declines in age-standardized incidence rates were apparent in the three oldest age groups, ranging from $11.97 \%(p=0.0377)$ in those aged 85 and older [from 74.53 to 65.61 per 1,000 to $15.40 \%(p=0.0396)$ in those aged $65-74$ (from 4.85 to 4.10 per 1,000)]. A significant decline of $18.97 \%(p=0.0136)$ in the age-standardized incidence rate among males was apparent only among those aged 65-74 (from 5.25 to 4.25 per 1,000). The population remained stable and neither sex in the 45-54 age group experienced significant changes in age-standardized incidence rates over time.

In terms of the databases where incident cases of dementia were first identified, the greatest proportion were first identified in Long-term Care in 2005/2006 (35.35\%) and 2012/2013 (34.98\%) (Table 2). The declines over time in the crude incidence rates per 1,000 were significant across every database with the exception of Prescription Drug, with similar declines in the Physician $(14.17 \% ; p=0.0007)$, Long-term Care $(14.14 \%$; $p=0.0002)$ and Hospital databases $(12.97 \% ; p=$ $0.0022)$.

\section{Prevalence}

Figure 2 shows that the overall age-standardized prevalence of dementia among those aged 45 and older increased between 2005/2006 to 2012/2013. Most of the increase took place in the first four years of the study period, with the upward trend slowing between 2009/2010 and 2012/2013. Over the 8-year period, the absolute number of overall prevalent cases rose $47.95 \%$ from 8,795 
to 13,012 , compared to an increase of $12.16 \%$ in the population from 411,918 to 462,024 (Tables 1 and 3). The overall age-standardized prevalence increased significantly $(p<0.0001)$ by $30.54 \%$ over time from 21.35 to 27.87 per 1,000 .

As shown in Table 3, the population increased slightly more among males than females (13.36\% vs. $11.05 \%$ ), as did the absolute number of prevalent cases $(51.22 \%$ vs. $46.03 \%)$. As a result, the age-standardized prevalence increased significantly $(p<0.0001)$ in both sexes, but to a slightly greater degree by $32.38 \%$ among males (from 20.51 to 27.15 per 1,000 ) compared to $29.48 \%$ among females (from 21.88 to 28.33 per 1,000). The proportion of prevalent cases attributed to males relative to females rose as well, from $36.94 \%$ to $37.76 \%(2.33 \%)$. However, the age-standardized incidence rate was slightly higher among females than males in $2005 / 2006$ (21.88 vs. 20.51 per 1,000 ) and remained so in $2012 / 2013$ (28.33 vs. 27.15 per 1,000 ).

Similar to increases in the population at risk for incident cases, the largest increases in the population at risk for prevalent cases took place in the 55-64 and 65-74 age groups. With the exception of the 45-54 age group, significant increases in age-standardized prevalence were apparent in every age group for both sexes. The largest increase in the age-standardized prevalence for both sexes took place in the 55-64 age group (107.08\% female, $p<0.0001 ; 48.72 \%$ male, $p<$ $0.0001)$ and the smallest increase was experienced by the 85 and older age group $(23.98 \%$ female, $p<$ $0.0001 ; 23.86 \%$ male; $p<0.0001)$.

\section{Discussion}

Using a population-based retrospective cohort design, we identified incident and prevalent cases of dementia between April 1, 2005 and March 31, 2013 in linked administrative health databases (Hospital Discharge Abstracts, Physician Service Claims, Prescription Drug, and RAI- MDS, i.e. Long-term Care), among individuals 45 years and older at first identification of dementia.

Considering the first study objective to investigate simultaneous age- and sex-specific temporal trends in dementia incidence and prevalence, we found the overall age-standardized incidence rate declined significantly by $11.07 \%$ and the agestandardized prevalence increased significantly by $30.54 \%$ over the 8 -year study period. Overall, the incidence rate declined from 8.41 to 7.48 per 1,000 despite an $11.38 \%$ increase in the overall population. Although both sexes experienced significant declines in the incidence rate over time, females experienced a slightly larger decrease than males $(12.97 \%$ vs. $8.39 \%)$. The age-standardized incidence rate remained higher among males than females in $2012 / 2013$ ( 7.84 vs. 7.23 per 1,000 ) as in $2005 / 2006$ ( 8.56 vs. 8.31 per 1,000 ). Among females, significant decreases occurred only in the three oldest age groups, with the largest decline in the 65-74 age group. Among males, only the 65-74 age group experienced a significant decline over the 8-year period.

Overall, the age-standardized prevalence of dementia increased significantly by $30.54 \%$ from 21.35 to 27.87 per 1,000 , and the population increased by $12.16 \%$ between 2005/2006 and $2012 / 2013$. Males experienced a slightly larger increase than females in the age-standardized prevalence over time $(32.38 \%$ vs. $29.48 \%)$. The age-standardized prevalence was higher among females than males in $2005 / 2006$ (21.88 vs. 20.51 per 1,000$)$ and remained so in $2012 / 2013(28.33$ vs. 27.15 per 1,000$)$. Significant increases were apparent in every age group for both sexes (except those 45-54), with the largest increment in the 5564 age group and the smallest increment in the 85 and older age group for both sexes.

Considering the second study objective to stratify the changes in incidence over the 8year study period by database of identification, significant decreases in the crude incidence rate per 1,000 were apparent in 3 of the 4 databases examined, with declines of $13-14 \%$ across Hospital Discharge Abstracts, Physician Service Claims, and RAI-MDS (i.e. Long-term Care).

\section{Incidence}

Our finding of declining dementia incidence over time is consistent with four original studies published within the last 10 years on the topic of incidence trends. Two were separate field studies (i.e. two-phase studies with screening followed by a structured clinical evaluation) in Rotterdam, the Netherlands (Schrijvers et al., 2012) and Stockholm, Sweden (Qiu et al., 2013); the third study was based on medical records in Rochester, US (Rocca et al., 2011) and the most recent study was based on administrative health data from the province of Ontario, Canada ( $\mathrm{Ng}$ et al., 2015). Compared to a $1.4 \%$ per year decline in the current study, incidence rates declined an average of 2.5$3 \%$ per year in two of the four studies (Rocca et al., 2011; Schrijvers et al., 2012), approximately $4.2 \%$ over a 7-year period in a third study $(\mathrm{Ng}$ et al., 2015), and an unspecified amount in a fourth study (Qiu et al., 2013). Similar to the present study, Schrijvers et al. (2012) observed a slightly greater decrease in the incidence rate over time in females 


\begin{tabular}{|c|c|c|c|c|c|c|c|c|c|c|c|c|c|c|c|}
\hline & \multicolumn{5}{|c|}{$2005 / 2006 n=8,795$} & \multicolumn{5}{|c|}{$2012 / 2013 n=13,012$} & \multicolumn{5}{|c|}{ CHANGE FROM 2005/2006 TO 2012/2013 (\%) } \\
\hline & $n$ & $\%$ & POPULATION & $\begin{array}{l}\text { CRUDE PREVALENCE } \\
\text { PER } 1,000\end{array}$ & $\begin{array}{l}\text { AGE-STANDARDIZED } \\
\text { PREVALENCE PER } 1,000\end{array}$ & $n$ & $\%$ & POPULATION & $\begin{array}{l}\text { CRUDE PREVALENCE } \\
\text { PER } 1,000\end{array}$ & $\begin{array}{l}\text { AGE-STANDARDIZED } \\
\text { PREVALENCE PER } 1,000\end{array}$ & $n$ & $\%$ & POPULATION & $\begin{array}{l}\text { AGE-STAND. } \\
\text { PREVALENCE } \\
\text { PER } 1,000\end{array}$ & $p$ VALUE $^{\mathrm{a}}$ \\
\hline Female & 5,546 & 63.06 & 213,312 & $26.00(25.33-26.68)$ & $21.88(21.21-22.45)$ & 8,099 & 62.24 & 236,881 & $34.19(33.46-34.93)$ & $28.33(27.73-28.94)$ & 46.03 & -1.36 & 11.05 & 29.48 & $<0.0001$ \\
\hline Male & 3,249 & 36.94 & 198,606 & $16.36(15.81-16.93)$ & $20.51(19.81-21.22)$ & 4,913 & 37.76 & 225,143 & $21.82(21.22-22.43)$ & $27.15(26.40-27.91)$ & 51.22 & 2.33 & 13.36 & 32.38 & $<0.0001$ \\
\hline \multicolumn{16}{|l|}{ Female } \\
\hline $45-54$ & 94 & 1.69 & 75,434 & $1.25(1.01-1.53)$ & $1.25(01.01-1.53)$ & 110 & 1.36 & 75,707 & $1.45(1.19-1.75)$ & $1.33(1.09-1.60)$ & 17.02 & -19.53 & 0.36 & 6.48 & 0.2733 \\
\hline $55-64$ & 163 & 2.94 & 52,090 & $3.13(2.67-3.65)$ & $3.12(2.66-3.64)$ & 446 & 5.51 & 68,404 & $6.52(5.93-7.15)$ & $6.47(5.88-7.09)$ & 173.62 & 87.41 & 31.32 & 107.08 & $<0.0001$ \\
\hline $65-74$ & 414 & 7.46 & 36,890 & $11.22(10.17-12.35)$ & $11.17(10.13-12.29)$ & 694 & 8.57 & 42,887 & $16.18(15.01-17.42)$ & $16.79(15.57-18.07)$ & 67.63 & 14.88 & 16.26 & 50.27 & $<0.0001$ \\
\hline $75-84$ & 1,623 & 29.26 & 31,110 & $52.17(49.73-54.70)$ & $51.30(48.90-53.79)$ & 2,034 & 25.11 & 29,801 & $68.25(65.42-71.18)$ & $66.75(63.97-69.61)$ & 25.32 & -14.18 & -4.21 & 30.11 & $<0.0001$ \\
\hline $85+$ & 3,252 & 58.64 & 17,788 & $182.82(177.16-188.58)$ & $179.17(173.63-184.82)$ & 4,815 & 59.45 & 20,082 & $239.77(233.88-245.73)$ & $222.14(216.68-227.66)$ & 48.06 & 1.38 & 12.90 & 23.98 & $<0.0001$ \\
\hline All ages & 5,546 & 100.00 & 213,312 & $26.00(25.33-26.68)$ & $21.88(21.21-22.45)$ & 8,099 & 100.00 & 236,881 & $34.19(33.46-34.93)$ & $28.33(27.73-28.94)$ & 46.03 & 0.00 & 11.05 & 29.48 & $<0.0001$ \\
\hline \multicolumn{16}{|c|}{ Male } \\
\hline $45-54$ & 88 & 2.71 & 77,504 & $1.14(0.91-1.40)$ & $1.13(0.91-1.39)$ & 101 & 2.06 & 77,693 & $1.30(1.06-1.58)$ & $1.19(0.97-1.45)$ & 14.77 & -23.99 & 0.24 & 5.39 & 0.3354 \\
\hline $55-64$ & 216 & 6.65 & 53,095 & $4.07(3.55-4.65)$ & $4.08(3.55-4.66)$ & 430 & 8.75 & 70,388 & $6.11(5.55-6.71)$ & $6.06(5.50-6.66)$ & 99.07 & 31.58 & 32.57 & 48.72 & $<0.0001$ \\
\hline $65-74$ & 438 & 13.48 & 34,559 & $12.67(11.52-13.91)$ & $12.74(11.58-13.98)$ & 697 & 14.19 & 41,702 & $16.71(15.51-17.99)$ & $17.52(16.25-18.86)$ & 59.13 & 5.27 & 20.67 & 37.54 & $<0.0001$ \\
\hline $75-84$ & 1,153 & 35.49 & 24,381 & $47.29(44.66-50.03)$ & $48.33(45.65-51.13)$ & 1,653 & 33.65 & 24,502 & $67.46(64.35-70.68)$ & $67.66(64.54-70.89)$ & 43.37 & -5.18 & 0.50 & 39.99 & $<0.0001$ \\
\hline $85+$ & 1,354 & 41.67 & 9,067 & $149.33(142.06-156.84)$ & $155.55(147.97-163.36)$ & 2,032 & 41.36 & 10,858 & $187.14(179.85-194.61)$ & $192.66(185.15-200.35)$ & 50.07 & -0.74 & 19.75 & 23.86 & $<0.0001$ \\
\hline All ages & 3,249 & 100.00 & 198,606 & $16.36(15.81-16.93)$ & $20.51(19.81-21.22)$ & 4,913 & 100.00 & 225,143 & $21.82(21.22-22.43)$ & $27.15(26.40-27.91)$ & 51.22 & 0.00 & 13.36 & 32.38 & $<0.0001$ \\
\hline \multicolumn{16}{|c|}{ Overall } \\
\hline $45-54$ & 182 & 2.07 & 152,938 & $1.19(1.02-1.38)$ & $1.19(1.02-1.38)$ & 211 & 1.62 & 153,400 & $1.38(1.20-1.57)$ & $1.26(1.10-1.44)$ & 15.93 & -21.74 & 0.30 & 5.97 & 0.1512 \\
\hline $55-64$ & 379 & 4.31 & 105,185 & $3.60(3.25-3.98)$ & $3.60(3.25-3.98)$ & 876 & 6.73 & 138,792 & $6.31(5.90-6.74)$ & $6.26(5.86-6.69)$ & 131.13 & 56.15 & 31.95 & 73.77 & $<0.0001$ \\
\hline $65-74$ & 852 & 9.69 & 71,449 & $11.93(11.14-12.75)$ & $11.93(11.14-12.75)$ & 1,391 & 10.69 & 84,589 & $16.44(15.60-17.32)$ & $17.15(16.26-18.06)$ & 63.26 & 10.32 & 18.39 & 43.77 & $<0.0001$ \\
\hline $75-84$ & 2,776 & 31.56 & 55,491 & $50.03(48.23-51.87)$ & $50.03(48.23-51.87)$ & 3,687 & 28.34 & 54,303 & $67.90(65.80-70.05)$ & $67.16(65.08-69.28)$ & 32.82 & -10.20 & -2.14 & 34.24 & $<0.0001$ \\
\hline $85+$ & 4,606 & 52.37 & 26,855 & $171.51(167.02-176.08)$ & $171.51(167.02-176.08)$ & 6,847 & 52.62 & 30,940 & $221.30(216.68-225.97)$ & $212.49(208.06-216.97)$ & 48.65 & 0.48 & 15.21 & 23.89 & $<0.0001$ \\
\hline All ages & 8,795 & 100.00 & 411,918 & $21.35(20.91-21.80)$ & $21.35(20.91-21.80)$ & 13,012 & 100.00 & 462,024 & $28.16(27.69-28.64)$ & $27.87(27.40-28.35)$ & 47.95 & 0.00 & 12.16 & 30.54 & $<0.0001$ \\
\hline
\end{tabular}

${ }^{\text {a }}$ Test of difference between age-standardized dementia prevalence in 2005/2006 versus 2012/2013. 
than males; however, in contrast to the present study, the incidence rate was higher among females than males at both time points.

\section{Prevalence}

The results of five original studies were in line with our finding of rising dementia prevalence over time, including separate field studies in Hisayama, Japan (Sekita et al., 2010) and northern Sweden (Mathillas et al., 2011) and administrative data studies in France (Bertrand et al., 2013) and the Canadian provinces of Alberta (Jacklin et al., 2013) and Ontario ( $\mathrm{Ng}$ et al., 2015). At $3.82 \%$ per year, the average annual growth in prevalence in the present study is in the lower range compared to other studies, which varied between $1.9-9.8 \%$ (Sekita et al., 2010; Mathillas et al., 2011; Bertrand et al., 2013; Jacklin et al., 2013; Ng et al., 2015). In the present study, males experienced a slightly larger increase than females in prevalence over time, whereas Sekita et al. (2010) observed the reverse. However, prevalence remained higher in females than males over time in the present study, in line with findings from two studies that observed increasing prevalence trends (Sekita et al., 2010; Mathillas et al., 2011).

Contrary to the results from the present study, three original studies reported a stable temporal trend in dementia prevalence, including an administrative health data study in Germany (Doblhammer et al., 2015) and separate field studies in Indianapolis, US (Hall et al., 2009) and Stockholm, Sweden (Qiu et al., 2013). An additional three original studies reported a downward temporal trend, namely separate field studies in a national US sample (Langa et al., 2008), Zaragoza, Spain (Lobo et al., 2007), and regions of England and Wales (Matthews et al., 2013).

\section{Possible explanations}

Recently published reviews and commentaries offer several possible explanations for decreasing dementia incidence and prevalence over time, as well as for increasing prevalence (Larson and Langa 2012; Banerjee 2013; Larson et al., 2013; Whalley and Smyth 2013; ADI, 2015; Lee 2014; Sachev 2014; Wu et al., 2015). Preliminary supporting evidence for these observations is provided by findings from several original studies, wherein some of these explanations were tested directly (Langa et al., 2008; Hall et al., 2009; Schrijvers et al., 2012; Elwood et al., 2013; Mathillas et al., 2011), and others wherein speculations were made on the basis of population-level trends and interventions in modifiable risk factors and other factors (e.g. demographics) (Lobo et al., 2007; Langa et al., 2008; Sekita et al., 2010; Rocca et al., 2011; Matthews et al., 2013; Qiu et al., 2013). First, cognitive reserve as an outcome of higher education and occupational complexity has been cited as a protective factor (Langa et al., 2008) and rising education levels and intellectual demands over time have been linked to declining incidence and prevalence of dementia in later cohorts (Langa et al., 2008; Hall et al., 2009; Rocca et al., 2011; Schrijvers et al., 2012; Matthews et al., 2013). In terms of the present study, education levels have been rising in Saskatchewan, reflected in an annual $2.8 \%$ growth in the proportion of post-secondary graduates aged 25-64 between 2000 and 2012 (Statistics Canada, 2013a).

Recent evidence from a 25-year longitudinal study supports an association between reduced risk of dementia and healthy lifestyle or behavior (e.g. non-smoking, physical activity, healthy diet, and limited alcohol intake) (Elwood et al., 2013). Increased uptake of healthy behaviors over time has been linked to declining dementia trends (Lobo et al., 2007; Hall et al., 2009; Qiu et al., 2013) as have reduced cardiovascular risks such as prevention of heart disease (Matthews et al., 2013), and decreased hypertension (Qiu et al., 2013), cholesterol (Qiu et al., 2013), and stroke (Rocca et al., 2011). However, a trend of increasing dementia prevalence in Japan has also been attributed to rising rates of obesity, hypercholesterolemia, and other metabolic disorders (Sekita et al., 2010). Population data indicate that while the rate of non-smoking, physical activity, and fruit/vegetable consumption increased in Saskatchewan over the study period, so too did the rates of obesity, diabetes, and high blood pressure (Statistics Canada, 2013b; Elliot, 2014).

Recent studies support an association between temporal trends of dementia decline and improved treatment of vascular risks (Lobo et al., 2007; Qiu et al., 2013) such as the use of antithrombotic and lipid-lowering drugs (Schrijvers et al., 2012), antihypertensive medications (Langa et al., 2008; Hall et al., 2009) and statins (Langa et al., 2008; Hall et al., 2009; Schrijvers et al., 2012). The most recent available population-level data for the study period indicate declining annual rates of mortality in Saskatchewan due to major cardiovascular diseases (Statistics Canada, 2014b), heart diseases, and cerebrovascular diseases (20032009) (Statistics Canada, 2013b).

Furthermore, increased dementia prevalence reflects lengthier duration of survival with dementia, possibly owing to improved care and treatment, such as better health services and institutional care (Sekita et al., 2010) and increased cholinesterase 
inhibitors prescriptions (Mathillas et al., 2011). Langa et al. (2008) proposed the "compression of cognitive morbidity" hypothesis that declining dementia trends demonstrate a delay of dementia to older age, reflecting the positive association over time between quality of life and brain health. Mathillas et al. (2011) suggested that better treatment of cardiovascular risks and reduced mortality due to cardiovascular disease contributed to a growing pool of Swedish older adults aged 85 and older at risk of dementia, thereby reflecting a trend of increasing dementia prevalence in this age cohort.

In terms of the present study, immigration accounted for $37.8 \%$ of total population growth in Saskatchewan between 2006 and 2011 (Statistics Canada, 2012). It is plausible that our observation of declining dementia incidence despite population growth was partly due to a limited recognition of dementia during encounters between healthcare professionals and older adult immigrants to Saskatchewan. It is also plausible that health selective migration, whereby older adult immigrants have better than average health (Norman et al., 2005), was partly responsible for this decline.

Variations in the direction and magnitude of change over time in incidence and prevalence across studies may be partly due to differences in diagnostic and classification criteria (Wu et al., 2014) and sample or population characteristics (e.g. age cut-offs, demographic trends in populations). For example, given the higher prevalence among institutionalized compared to communitydwelling populations (Hoffman et al., 2014), excluding nursing home residents in field studies (e.g. Langa et al., 2008; Hall et al., 2009) possibly underestimates dementia prevalence overall. Methodological approaches (e.g. observation periods) may also contribute to variations. For instance, in comparison to field studies, administrative health data studies such as the present study tend to underestimate the true number of individuals with dementia because dementia tends to be underrecognized in the healthcare system (Lambert et al., 2014). Moreover, evidence in some high income nations of declining incidence trends (Rocca et al., 2011; Schrijvers et al., 2012; Qiu et al., 2013) and stable or downward prevalence trends (Lobo et al., 2007; Langa et al., 2008; Hall et al., 2009; Matthews et al., 2013; Qiu et al., 2013; Doblhammer et al., 2015), may reflect a positive association between national wealth, public health, and healthcare and therefore hinder generalization of findings to low and middle income countries where population aging and cardiovascular risk factors tend to be on the rise (ADI, 2015; Wu et al., 2015).
Several interrelated factors potentially account for the limited impact of the declining dementia incidence rate on the prevalence of dementia in the current study. The primary explanation may be that the 8-year observation period was too brief to demonstrate an impact. Second, rising prevalence despite declining incidence in the present study indicates that survival time with dementia was also increasing, from 2.56 years in $2005 / 2006(21.53 / 8.41$ in $2005 / 2006)$ to 3.73 years in 2012/2013 (27.87/7.48). Increased survival time and prevalence may be due to identification of dementia in earlier stages (ADI, 2015) and improved treatment after identification. Lastly, the declining provincial mortality rate and growth of the overall population aged 45 and older minimized the impact of declining incidence upon prevalence during the short 8year observation period. Beginning in 2009/2010, declining incidence may have begun to manifest in a relatively slower increase in prevalence compared to pre-2009/2010, perhaps signaling the beginning of a stabilizing trend in dementia prevalence.

\section{Limitations}

Administrative health data is collected for purposes other than disease surveillance, and as such, several limitations are associated with the use of administrative health data to determine incidence and prevalence of dementia. First, underdiagnosis of dementia is a significant issue, with studies showing that $31-69 \%$ of primary care patients with dementia do not receive a formal documented diagnosis (Boustani et al., 2003; Bradford et al., 2009; van den Dungen et al., 2012). Moreover, physician services claims permit a maximum of one diagnosis code per claim, therefore diseases due to dementia may not be captured in these claims if patients present with other problems. As a result, studies based on administrative health data tend to produce underestimations of prevalence and incidence in comparison to field studies (Lambert et al., 2014). However, data linkage across sectors is possible in administrative health data studies, allowing community and institutiondwelling populations to be examined as a whole for a more complete picture of dementia epidemiology, in contrast to field studies which may not combine these populations (e.g. Langa et al., 2008; Hall et al., 2009). Second, all of the data sources in the present study included the Registered Indian population, with the exception of the prescription drug database. However, Registered Indians who were not identified as cases in the prescription drug database were likely identified in one of the other three administrative health databases. 
Therefore, their exclusion from the prescription drug database may have contributed to a minor underestimation of the increase in prevalence over the study period given the faster rise in dementia prevalence over time in First Nations compared to non-First Nations documented by Jacklin and colleagues (2013). Third, individuals excluded from the cohort due to interrupted health insurance coverage (i.e. a gap in insurance coverage of more than 3 days) accounted for $4.2 \%$ of the total cohort over the study period. Compared to individuals without gaps, those with gaps were more likely to be male $(40.4 \%$ with no gap vs. $45.1 \%$ with gap) and Registered Indian $(2.1 \%$ with no gap vs. $9.7 \%$ with gap). Registered Indians comprised only $2.4 \%$ of the dementia cohort and therefore the overall estimates of incidence and prevalence reported in the present study were not likely affected. However, despite the small proportion of people excluded from the study, the sex-specific estimates of prevalence were likely to have been affected because of the additive effect of disproportionately excluding men. Specifically, each year the prevalence of dementia will be further underestimated in men compared to women because each year, just a few more men than women will be excluded. The difference in the prevalence of dementia between men and women will appear more pronounced with each passing year. Fourth, excluding a prescription of memantine from the case definition algorithm may have resulted in a slight underestimation of prevalence and incidence, in cases that had not been identified with a cholinesterase prescription or in one of the other three databases. Finally, our study period of 8 years may be too short to discern a consistent and reliable pattern or trend in dementia over time.

\section{Conclusions}

Despite some limitations, administrative health data is a valuable research tool for tracking trends in dementia incidence and prevalence. The present study demonstrated that over an 8-year period in the province of Saskatchewan, the agestandardized incidence rate of dementia declined among individuals aged 45 and older while the age-standardized prevalence of dementia simultaneously increased. These trends indicate that the average survival time with dementia was also increasing, suggesting the possibilities that recognition of dementia is taking place in earlier stages and treatment is improving. As individuals live longer with dementia, similar to other chronic diseases, they require active care and monitoring for an extended period of time (Bergman, 2009; ADI, 2014). To spur improvements in dementia care and address increasing cost burdens, several G7 nations have developed national dementia strategies (France, Japan, United Kingdom, United States, Italy). Canada currently does not have a national dementia plan, despite an estimated 500,000 Canadians living with dementia in 2008 and over 100,000 incident cases developing each year (Dudgeon, 2010). Further reduction in dementia incidence is certainly possible with the type of concentrated focus that a national strategy promises, and future research should track these developments.

\section{Conflict of interest}

None.

\section{Description of authors' roles}

J. Kosteniuk, D. Morgan, J. Quail, and G. Teare conceived of the study. J. Quail and G. Teare acquired the data and J. Quail performed the analyses. J. Kosteniuk, D. Morgan, J. Quail, M. O'Connell, A. Kirk, and M. Crossley constructed the algorithm for case identification. J. Kosteniuk, D. Morgan, J. Quail, M. O'Connell, A. Kirk, M. Crossley, G. Teare, N. Stewart, V. Dal BelloHaas, L. McBain. H. Mou, D. Forbes, and A. Innes undertook the study design and data interpretation. J. Kosteniuk wrote the initial draft of the manuscript. All authors critically revised the manuscript, read, and approved the final manuscript.

\section{Disclaimer}

This study is based in part on de-identified data provided by the Saskatchewan Ministry of Health through the Health Quality Council. The interpretation and conclusions contained herein do not necessarily represent those of the Government of Saskatchewan or the Saskatchewan Ministry of Health.

\section{Acknowledgments}

Study funding was provided by an Applied Chair in Health Services and Policy Research Award to DGM from the Saskatchewan Health Research Foundation (\#2104) and Canadian Institutes of Health Research (\#ACH 93185). JMQ and GFT are both employed by the Saskatchewan Health Quality Council which contributed, in-kind, portions of their time for this project. 


\section{References}

Aboriginal Affairs and Northern Development Canada. (2013). Registered Indian Population by Sex and Residence 2012. Available at: https://www.aadnc-aandc.gc.ca/eng/ 1373985023065/1373985196078; last accessed 21 May 2015.

Alzheimer's Disease International. (2011). World Alzheimer Report 2011: The Benefits of Early Diagnosis and Intervention. Available at: http://www.alz.co.uk/research/world-report-2011; last accessed 21 May 2015.

Alzheimer's Disease International. (2014). World Alzheimer Report 2014: Dementia and Risk Reduction. Available at: http://www.alz.co.uk/research/world-report-2014; last accessed 21 May 2015.

Alzheimer's Disease International. (2015). World Alzheimer Report 2015: The Global Impact of Dementia. Available at: http://www.alz.co.uk/research/world-report-2015; last accessed 8 November 2015.

Banerjee, S (2013). Good news on dementia prevalence - we can make a difference. Lancet, 382, 1384-1386. doi:10.1016/S0140-6736(13)61579-2.

Bartfay, E., Bartfay, W. and Gorey, K. (2013). Prevalence and correlates of potentially undetected dementia among residents of institutional care facilities in Ontario, Canada, 2009-2011. International fournal of Geriatric Psychiatry, 28, 1086-1094. doi:10.1002/gps.3934.

Bergman, H. (2009). Meeting the challenge of Alzheimer's Disease and related disorders. Report of the Committee of Experts for the Development of an Action Plan on Alzheimer's Disease and Related Disorders. Available at: http://www.alzheimer.ca/en/montreal/About-us/ /media/D6DF412C089F4C1995014784D532BAD7.ashx; last accessed 21 May 2015.

Bertrand, M., Tzourio, C. and Alperovitch, A. (2013). Trends in recognition and treatment of dementia in France Analysis of the 2004 to 2010 Database of the National Health Insurance Plan. Alzheimer Disease and Associated Disorders, 27, 213-217. doi:10.1097/WAD.0b013e3182695a3b.

Bidwell, L., McClernon, F. and Kollins, S. (2011). Cognitive enhancers for the treatment of ADHD. Pharmacology, Biochemistry and Behavior, 99, 262-274. doi:10.1016/j.pbb.2011.05.002.

Boustani, M., Peterson, B., Hanson, L., Harris, R. and Lohr, K. (2003). Screening for dementia in primary care: a summary of the evidence for the U.S. Preventive Services Task Force. Annals of Internal Medicine, 138, 927-937. doi:10.7326/0003-4819-138-11-200306030-00015.

Bradford, A., Kunik, M., Schulz, P., Williams, S. and Singh, H. (2009). Missed and delayed diagnosis of dementia in primary care: prevalence and contributing factors. Alzheimer Disease and Associated Disorders, 23, 306-314. doi:10.1097/WAD.0b013e3181a6bebc.

Canadian Study of Health and Aging Working Group (CSHA). (2000). The incidence of dementia in Canada. Neurology, 55, 66-73. doi:10.1212/WNL.55.1.66.

Chartier, M. et al. (2012). Health and Healthcare Utilization of Francophones in Manitoba. Winnipeg, Manitoba: Manitoba Centre for Health Policy.
Chertkow, H., Feldman, H., Jacova, C. and Massoud, F. (2013). Definitions of dementia and predementia states in Alzheimer's disease and vascular cognitive impairment: consensus from the Canadian conference on diagnosis of dementia. Alzheimer's Research $\mathcal{E}$ Therapy, 5(Suppl. 1), S2. doi:10.1186/alzrt198.

Connolly, A., Gaehl, E., Martin, H., Morris, J. and Purandare, N. (2011). Underdiagnosis of dementia in primary care: variations in the observed prevalence and comparisons to the expected prevalence. Aging and Mental Health, 15, 978-984. doi:10.1080/13607863.2011.596805.

Doblhammer, G., Fink, A. and Fritze, T. (2015). Short-term trends in dementia prevalence in Germany between the years 2007 and 2009. Alzheimer's E Dementia, 11, 291-299. doi: 10.1016/j.jalz.2014.02.006.

Downey, W., Stang, M., Beck, P., Osei, W. and Nichol, J. (2005). In B. Strom (ed.), Pharmacoepidemiology, 4th edn. Mississauga, Ontario: John Wiley \& Sons.

Ducharme, F., Kergoat, M. J., Antoine, P., Pasquier, F. and Coulombe, R. (2014). Caring for individuals with early-onset dementia and their family caregivers: the perspective of health care professionals. Advances in Alzheimer's Disease, 3, 33-43. doi:10.4236/aad.2014.31005.

Dudgeon, S. (2010). Rising Tide: The Impact of Dementia on Canadian Society. Toronto, Ontario: Alzheimer Society.

Elliott, D. (2014). Sask Trends Monitor fune 2014. Regina, Saskatchewan.

Elwood, P. et al. (2013). Healthy lifestyles reduce the incidence of chronic diseases and dementia: evidence from the caerphilly cohort study. Plos One, 8, e81877. doi:10.1371/journal.pone.0081877.

Fransoo, R., Martens, P., Burland, E., The Need to Know Team, Prior, H. and Burchill, C. (2009). Manitoba RHA Indicators Atlas 2009. Winnipeg, Manitoba: Manitoba Centre for Health Policy.

Gill, S., Camacho, X. and Poss, J. (2011)

Community-dwelling older adults with dementia: tracking encounters with the health system. In S. Bronskill, X. Camacho, A. Gruneir and M. Ho (eds.), Health System Use by Frail Ontario Seniors: An In-Depth Examination of Four Vulnerable Cohorts. Toronto, Ontario: Institute for Clinical Evaluative Sciences.

Hall, K. et al. (2009). Prevalence rates for dementia and Alzheimer's disease in African Americans: 1992 versus 2001. Alzheimer's and Dementia, 5, 227-233. doi:10.1016/j.jalz.2009.01.026.

Hoffman, F., Kaduszkiewicz, H. Kaduszkiewicz, Glaeske, G., van den Bussche, H. and Koller, D. (2014). Prevalence of dementia in nursing home and community-dwelling older adults in Germany. Aging Clinical and Experimental Research, 26, 555-559. doi:10.1007/s40520-014-0210-6.

Hogan, D. (2014). Long-term efficacy and toxicity of cholinesterase inhibitors in the treatment of Alzheimer disease. Canadian Fournal of Psychiatry, 59, 618-623.

Jacklin, K., Walker, J. and Shawande, M. (2013). The emergence of dementia as a health concern among first nations populations in Alberta, Canada. Canadian fournal of Public Health, 104, e39-e44. doi:http://dx.doi.org/10.17269/cjph.104.3348.

Kosteniuk, J. G. et al. (2015). Incidence and prevalence of dementia in linked administrative health data in 
Saskatchewan, Canada: a retrospective cohort study. BMC Geriatrics, 15, 73. doi:10.1186/s12877-015-0075-3.

Lambert, M. et al. (2014). Estimating the burden of early onset dementia: systematic review of disease prevalence. European fournal of Neurology, 21, 563-569. doi:10.1111/ene.12325.

Langa, K. et al. (2008). Trends in the prevalence and mortality of cognitive impairment in the United States: is there evidence of a compression of cognitive morbidity? Alzheimer's and Dementia, 4, 134-144. doi:10.1016/j.jalz.2008.01.001.

Larson, E. and Langa, K. (2012). Aging and incidence of dementia (Editorial). Neurology, 78, 1452-1453. doi:10.1212/WNL.0b013e318256c00d.

Larson, E., Yaffe, K. and Langa, K. (2013). New insights into the dementia epidemic. New England fournal of Medicine, 369, 2275-2277. doi:10.1056/NEJMp1311405.

Lee, Y. (2014). The recent decline in prevalence of dementia in developed countries: implications for prevention in the republic of Korea. Fournal of Korean Medical Science, 29, 913-918. doi:10.3346/jkms.2014.29.7.913.

Lee, P., Hsiung, G., Seitz, D., Gill, S. and Rochon, P. (2011). Cholinesterase inhibitors. BC Medical fournal, 53, 404-408.

Lobo, A. et al. (2007). Prevalence of dementia in a southern European population in two different time period: the ZARADEMP Project. Acta Psychiatrica Scandinavia, 116, 299-307. doi:10.1111/j.1600-0447.2007.01006.x.

Manitoba Centre for Health Policy. (2012). Dementia concept description; 2012. Available at: http://mchp-appserv.cpe.umanitoba.ca/viewConcept.php? conceptID=1179; last accessed 21 June 2015.

Martens, P. et al. (2010). Profile of Metis Health Status and Healthcare Utilization in Manitoba: A Population-Based Study. Winnipeg, MB: Manitoba Centre for Health Policy.

Mathillas, J., Lovheim, H. and Gustafson, Y. (2011). Increasing prevalence of dementia among very old people. Age and Ageing, 40, 243-249. doi:10.1093/ageing/afq173.

Matthews, F. et al. (2013). A two-decade comparison of prevalence of dementia in individuals aged 65 years and older from three geographical areas of England: results of the cognitive function and ageing study I and II. Lancet, 382, 1405-1412. doi:10.1016/S0140-6736(13)61570-6.

Morris, J. et al. (1994). MDS cognitive performance scale. fournal of Gerontology, 49, M174-M182. doi:10.1093/geronj/49.4.M174.

Morris, J. N. et al. (2010). Resident Assessment Instrument (RAI) RAI-MDS 2.0 User's Manual. Canadian Version. Washington DC: interRAI.

Ng, R. et al. (2015). Brain Disorders in Ontario: Prevalence, Incidence and Costs from Health Administrative Data. Toronto, ON: Institute for Clinical Evaluative Sciences.

Norman, P., Boyle, P. and Rees, P. (2005). Selective migration, health and deprivation: a longitudinal analysis. Social Science and Medicine, 60, 2755-2771.

doi:10.1016/j.socscimed.2004.11.008.

Norton, S., Matthews, F. and Brayne, C. (2013). A commentary on studies presenting projections of the future prevalence of dementia. BMC Public Health, 13, 1. doi:10.1186/1471-2458-13-1.

Paquay, L., De Lepeleire, J., Schoenmakers, B., Ylieff, M., Fontaine, O. and Buntinx, F. (2007). Comparison of the diagnostic accuracy of the cognitive performance scale (Minimum Data Set) and the mini-mental state exam for the detection of cognitive impairment in nursing home residents. International fournal of Geriatric Psychiatry, 22, 286-293. doi:10.1002/gps.1671.

Perneczky, R., Wagenpfeil, S., Komossa, K., Grimmer, T., Diehl, J. and Kurz, A. (2006). Mapping scores onto stages: mini-mental state examination and clinic dementia rating. American fournal of Geriatric Psychiatry, 14, 139-144. doi:10.1097/01.JGP.0000192478.82189.a8.

Qiu, C., Strauss, E., Backman, L., Winblad, B. and Fratiglioni, L. (2013). Twenty-year changes in dementia occurrence suggest decreasing incidence in central Stockholm, Sweden. Neurology, 80, 1888-1894. doi:10.1212/WNL.0b013e318292a2f9.

Rocca, W. et al. (2011). Trends in the incidence and prevalence of Alzheimer's disease, dementia, and cognitive impairment in the United States. Alzheimer's and Dementia, 7, 80-93. doi:10.1016/j.jalz.2010.11.002.

Sachev, P. (2014). Is the Incidence of Dementia Declining? A Report for Alzheimer's Australia. Available at: https://cheba. unsw.edu.au/sites/default/files/cheba/blog/Is $\% 20$ the $\%$ 20 incidence $\% 20$ of $\% 20$ dementia $\% 20$ declining_Report $\%$ 20 for $\% 20$ Alzheimer $\% 27 \mathrm{~s} \% 20$ Australia.pdf; last accessed 21 May 2015.

Saskatchewan Bureau of Statistics. (2014). Saskatcherwan Population by 5 Year Age Groups, 2003 to 2013. Available at: http://www.stats.gov.sk.ca/pop/; last accessed 21 May 2015.

Saskatchewan Bureau of Statistics. (2015). Saskatchewan Fact Sheet, Fuly 2015. Available at: http://www.stats.gov.sk.ca/Default.aspx?DN= b2e511d6-2c66-4f7d-9461-69f4bffd3629; last accessed 8 Nov 2015.

Saskatchewan Ministry of Health. (2010). Health Services Databases: Information Document. Available at: http://www.health.gov.sk.ca/health-databases-info-doc; last accessed 21 May 2015.

Saskatchewan Ministry of Health. (2012). Covered Population 2012. Available at: http://www.ehealthsask.ca/ HealthRegistries/Pages/Covered-Population.aspx; last accessed 8 Nov 2015.

Schrijvers, E., Verhaaren, B., Koudstaal, P., Hofman, A., Ikram, M. and Breteler, M. (2012). Is dementia incidence declining? Trends in dementia incidence since 1990 in the Rotterdam study. Neurology, 78, 1456-1463. doi:10.1212/WNL.0b013e3182553be6.

Sekita, A. et al. (2010). Trends in prevalence of Alzheimer's disease and vascular dementia in a Japanese community: the Hisayama Study. Acta Psychiatrica Scandinavia, 122, 319-325. doi:10.1111/j.1600-0447.2010.01587.x.

St. Germaine-Smith, C. et al. (2012). Recommendations for optimal ICD codes to study neurologic conditions: a systematic review. Neurology, 79, 1049-1055. doi:10.1212/WNL.0b013e3182684707.

Statistics Canada. (2012). The Canadian Population in 2011: Population Counts and Growth (Cat. no. 98-310-X2011001). Ottawa: Minister of Industry.

Statistics Canada. (2013a). Education Indicators in Canada: An International Perspective 2013 (Cat. no. 81-604-X). Ottawa: Minister of Industry.

Statistics Canada. (2013b). Health Trends, Saskatchewan (Cat. no. 82-213-X). Ottawa: Minister of Industry. 
Statistics Canada. (2014a). Annual Demographic Estimates: Subprovincial Areas 2006 to 2013 (Cat. no. 01-214-X). Ottawa: Minister of Industry.

Statistics Canada. (2014b). Table 102-0552 - Deaths and Mortality Rate, by Selected Grouped Causes and Sex, Canada, Provinces and Territories, Annual. Available at: http://www5.statcan.gc.ca/cansim/a26?lang=eng\&id= 1020552; last accessed 19 May 2015.

Travers, C., Byrne, G., Pachana, N., Klein, K. and Gray, L. (2013) Validation of the interrai cognitive performance scale against independent clinical diagnosis and the mini-mental state examination in older hospitalized patients. Fournal of Nutrition Health and Aging, 17, 435-439. doi:10.1007/s12603-012-0439-8.

Tyas, S., Tate, R., Wooldrage, K., Manfreda, J. and Strain, L. (2006). Estimating the incidence of dementia: the impact of adjusting for subject attrition using health care utilization data. Annals of Epidemiology, 16, 477-484. doi:10.1016/j.annepidem.2005.09.006. van den Dungen, P. et al. (2012). The accuracy of family physicians' dementia diagnoses at different stages of dementia: a systematic review. International fournal of Geriatric Psychiatry, 27, 342-354. doi:10.1002/gps.2726.

Whalley, L. and Smyth, K. (2013). Human culture and the future dementia epidemic (Editorial). Neurology, 80, 1824-1825. doi:10.1212/WNL.0b013e318292a368.

World Health Organization and Alzheimer's Disease International. (2012). Dementia: A Public Health Priority. Available at: http://www.who.int/mental_health/ publications/dementia_report_2012/en/; last accessed 21 May 2015.

Wu, Y. et al. (2015). Dementia in western Europe: epidemiological evidence and implications for policy making. Lancet Neurology, doi:10.1016/ S1474-4422(15)00092-7.

Wu, Y., Matthews, F. and Brayne, C. (2014). Dementia: time trends and policy responses. Maturitas, 79, 191-195. doi: http://dx.doi.org/10.1016/j.maturitas.2014.06.020. 